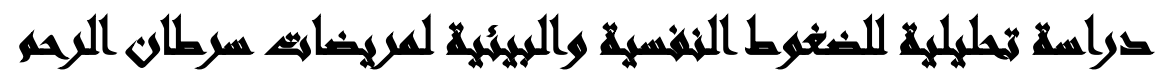

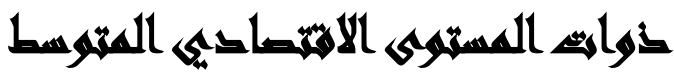

[1r]

$$
\begin{aligned}
& \text { ليلى أحمد السيد كرم الدين(')- إيهاب محمد عيد(')- هبة صلاح بشير حسن } \\
& \text { () كلية الدراسات العليا للطفولة، جامعة عين شمس الدم (1) } \\
& \text { المستحلى }
\end{aligned}
$$

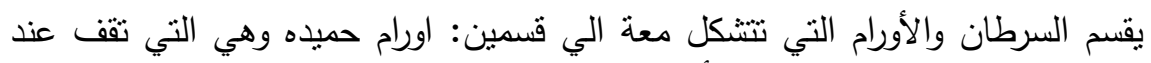

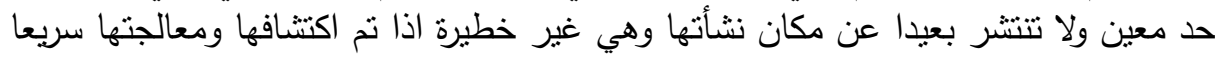

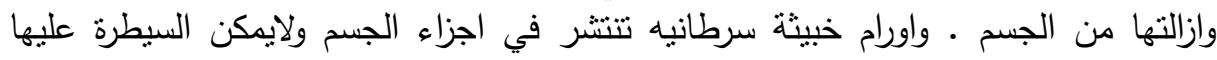

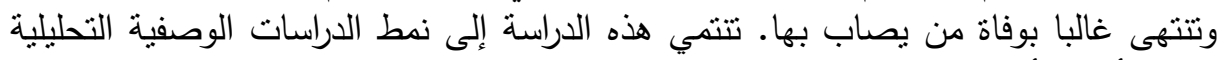

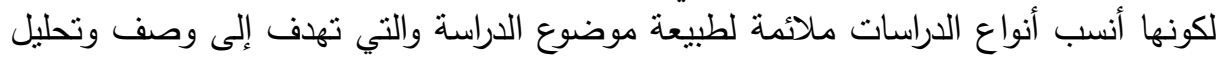

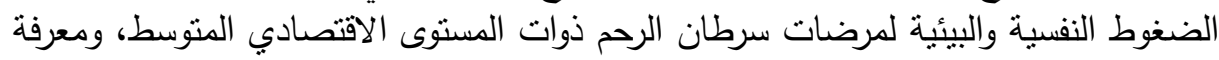

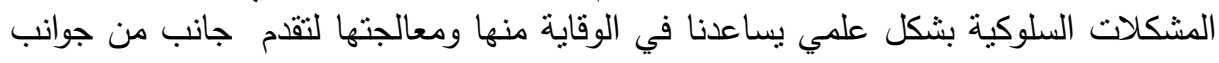

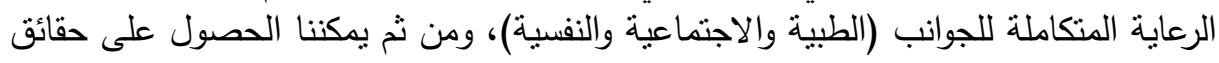

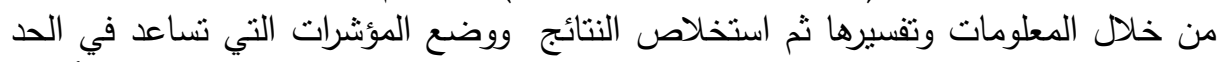

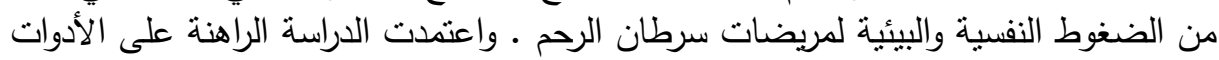

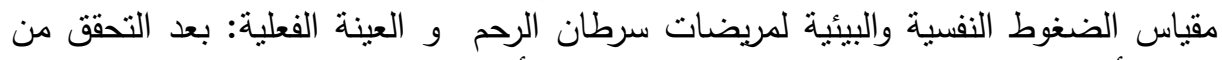

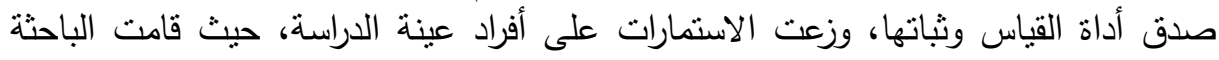

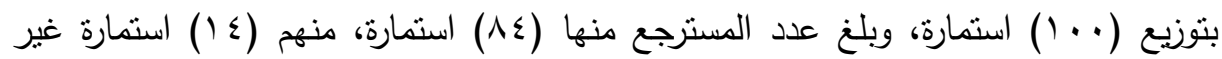

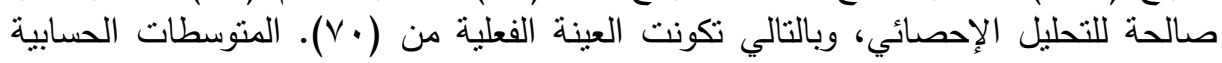

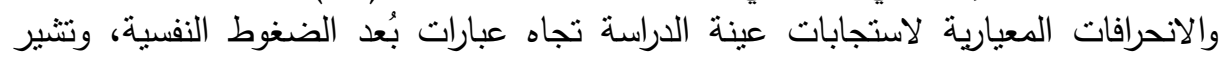

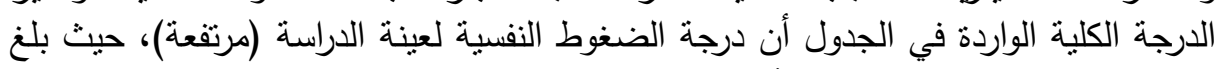

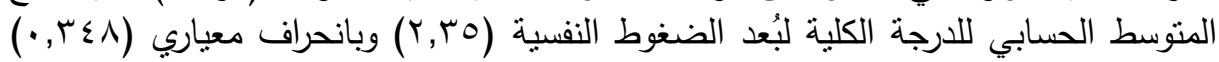

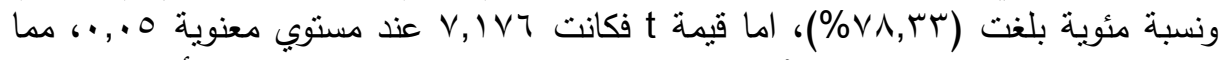

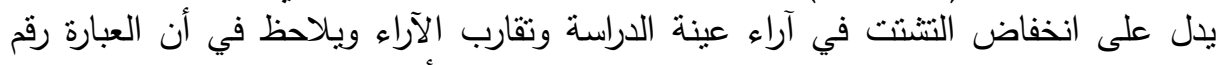

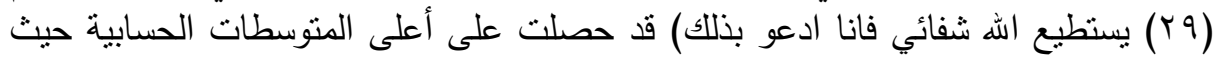

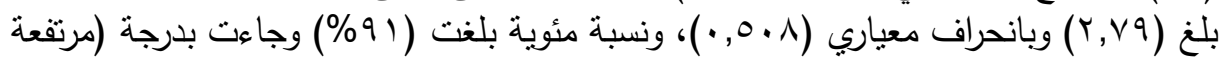

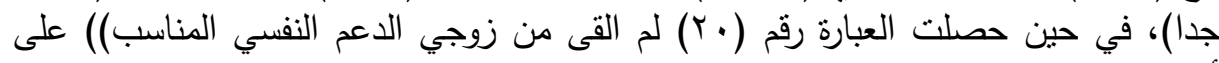

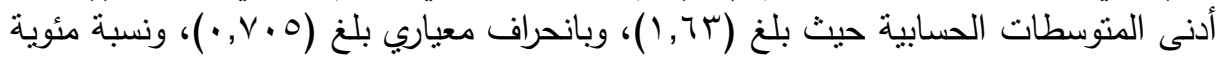

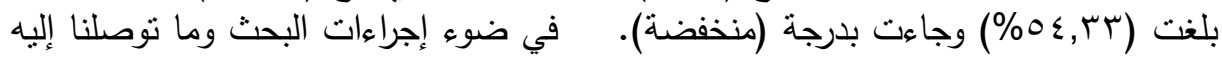

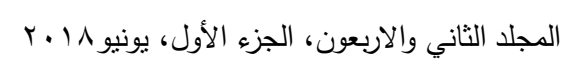




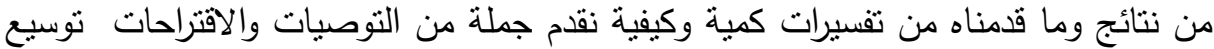

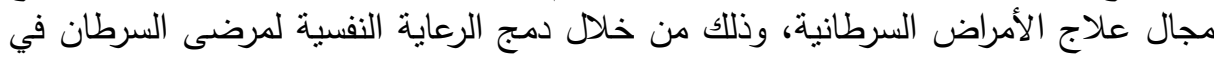

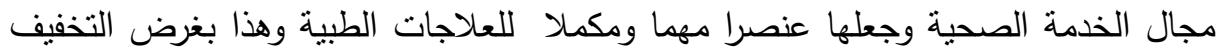
من حدة التوترات الانفعالية والمشاكل النفسية التي قد يتعرض لها المرضى نتيجة الإصابة

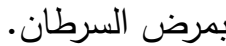
الكلمات المفتاحية: الضغوط النفسية- الضغوط البيئية - سرطان الرحم

\section{Xasing}

مرض السرطان هو مرض يصيب خلايا الجسم، فخلايا الجسم الطبيعية تتمو وتتقسم بطريقة منظمة عن طريق الجينات المتواجدة داخل نواة الخلية، فإذا حدث خلل في التركيب الجيني للخلية هذا يفقدها السيطرة والتحكم على هذه العمليات مما يؤدي الي النمو السريع

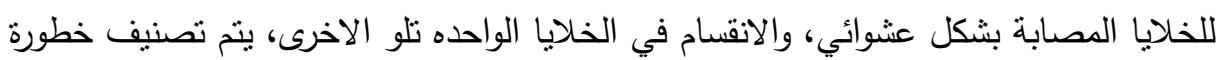

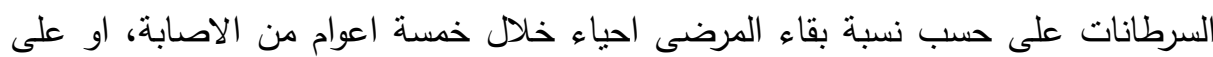

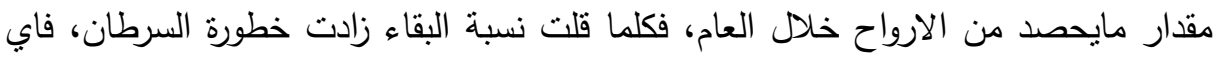

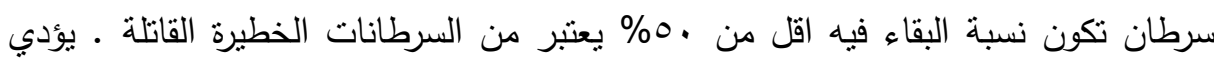
سرطان الرحم لاعراض عديدة ابرزها النزيف المهبلي، تكتثف معظم حالات سرطان الرحم في

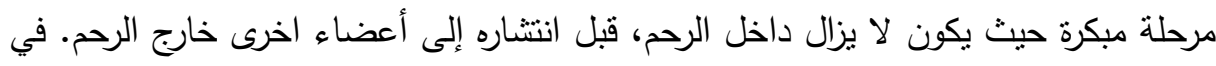

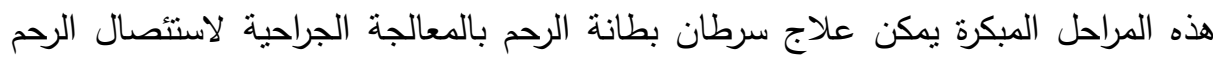

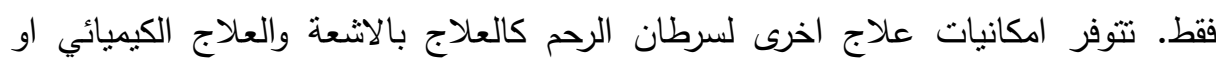

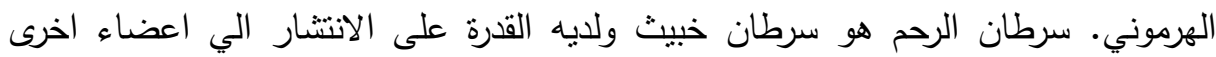

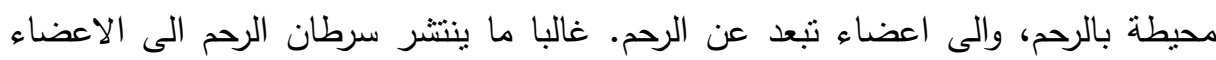
المجاورة كعنق الرحم،المبيض، او قنوات فالوب وهي الانابيب التى تصل الى الى الرحم والمبيض. الحوض: قد ينتشر سرطان الرحم الى الحوض وجوف البطن وذلك بعد انتقال الخلايا

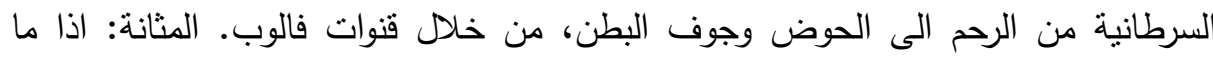
انتشر سرطان الرحم الى المثانة ،يؤدي لاعراض تتعلق بالمثانة كعسر البرول، والحاح البول

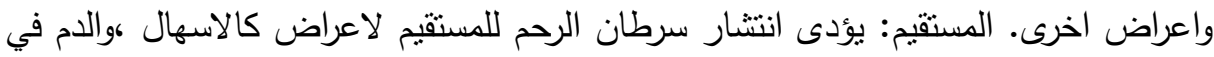


البراز. العقد اللدفاوية: قد ينتشر سرطان الرحم الى العقد اللدفاوية في الحوض ويؤدي

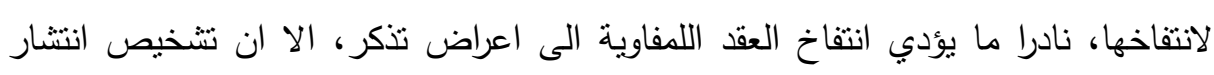

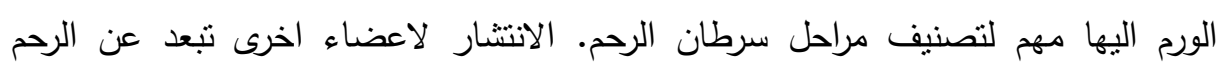

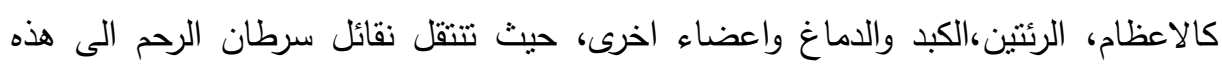
الاعضاء عن طريق الاوعية الدموية.

\section{همشعلة الدراسمة}

إن مرضى السرطان بانواعه وخاصة مرضى سرطان الرحم كثيرا ما يلعب الاحباط

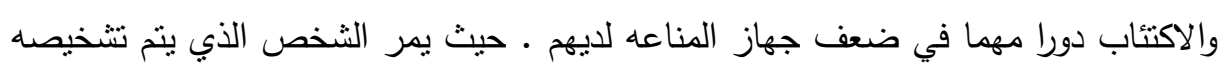

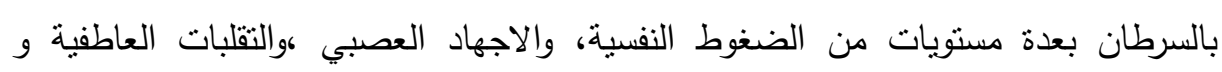
الثعورية،والقلق العصبي ،والتغيرات الجذرية في نمط الحياة، والخوف من الموت والتغيرات الجسدية او تغير الثكل البدني وتغير النظرة الى الذات والتغير في الموقع والوضع الاجتماعي نواني وطريقة الحياة . (2012:Hill).

ان الرحم هوعضو من الجهاز التتاسلي الانثوي ،ويقع الرحم في الحوض بين المثانة

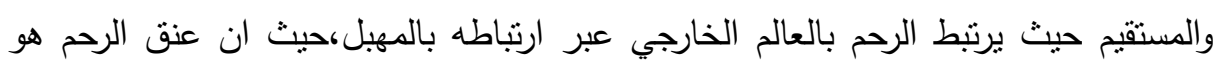

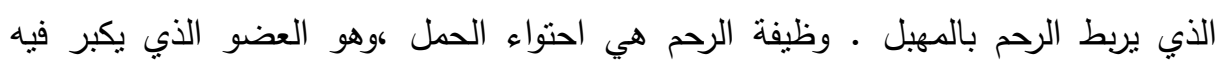

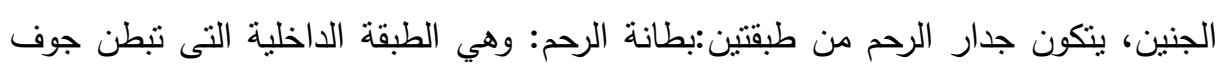

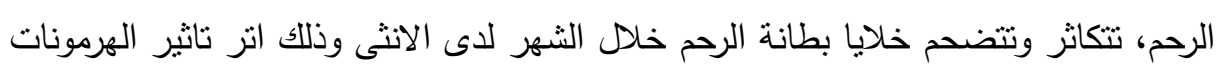

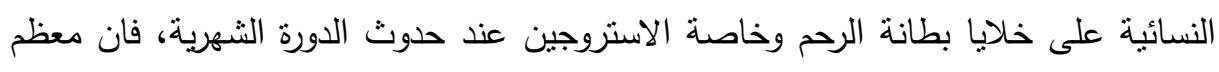

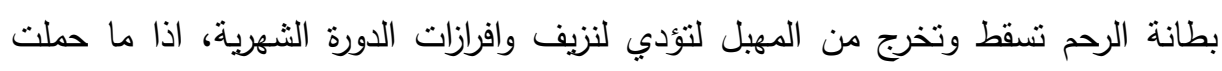

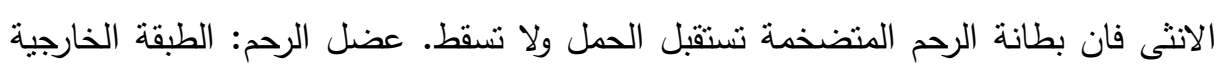

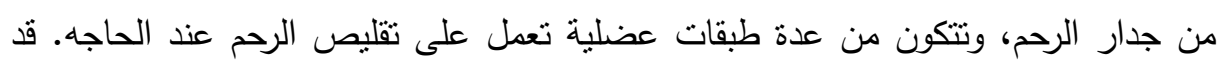

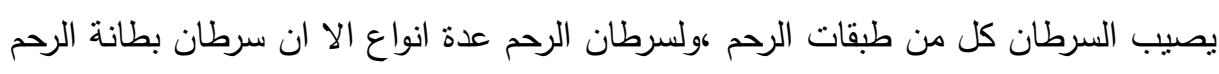

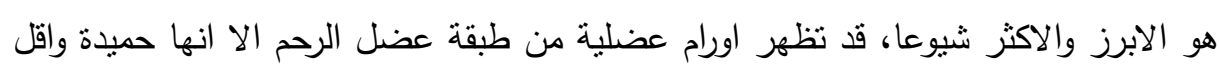

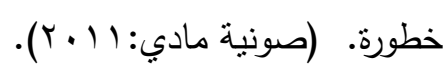


وعلى الرغم من خطورة المرض الا ان تكلفة العلاج عالية جدا تفوق قدرات الفقراء

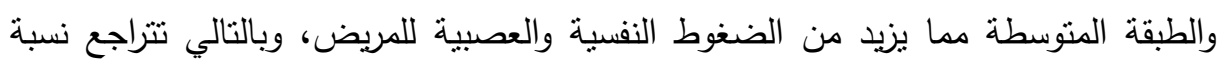
الثفاء. بجانب ضعف الامكانيات المادية لدى المريض ياتي ايضا قلة الوعي تجاه المرض.

\section{توساولاهت التصاسما}

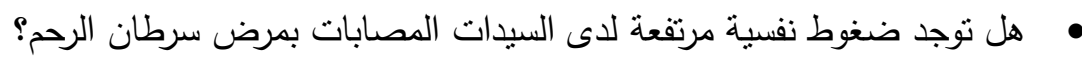

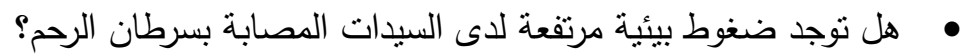

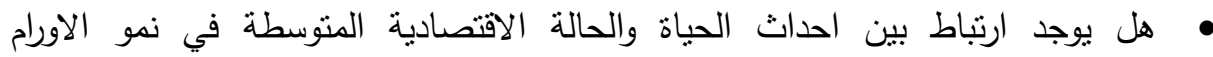

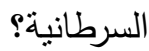

\section{هزوض القواسمة}

• توجد علاقة ذات دلالة احصائية ايجابية بين اورام سرطان الرحم وبين الضغوط النفسية. • توجد علاقة ذات دلالة احصائية ايجابية بين اورام سرطان الرحم وبين الضغوط البين البيئية.

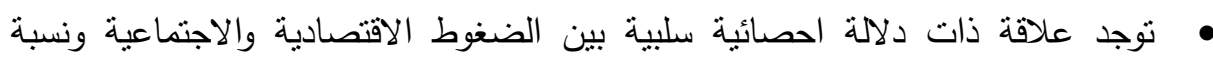
حدوث اورام سرطان الرحم.

\section{أهساهن التواسمة}

• دراسة المشكلات المعرفية والسلوكيه التى تواجه السيدات المصابات بسرطان الرحم •

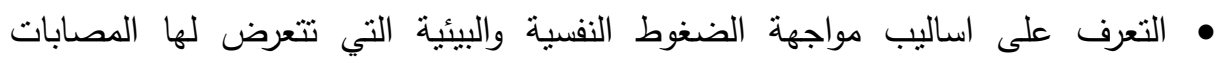
بسرطان الرحم. • التعرف على اساليب لمواجهة الضغوط الاقتصاديه لمرضى سرطان الرحم • لمعن

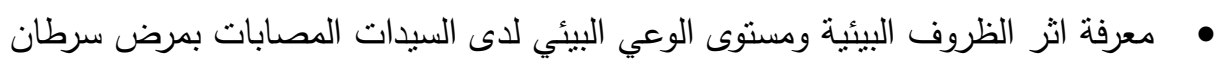
الرحم. 


\section{أهمية التواسمة}

التعرف على سرطان الرحم وكيفية حدوثه، واعراضه ،وخطورته على المرأة وكيفيه الوقاية

$$
\text { من حدوثة. }
$$

التعرف على العوامل النفسية التى تؤثز على السيدات المصابات بمرض سرطان الرحم والعوامل المساعدة على مقاومة هذا المرض.

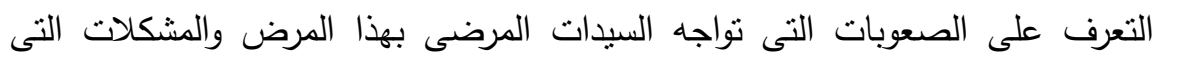

$$
\text { تعوق توافقهم البيئي. }
$$

\section{همطللحاهي القوراسة}

الضغط (الإتعصاب): هو حالة المحنة تعصب المرء اي تشتن به، ويقال لأمر انه عصيب، أي شديد والمحنة شدة تنزل بالمرء فينعصب بها او يمحن، أي يتوتز ويقلق وتستنفز دفاعاته البدنية والنفسية ينوسل بها للتهايؤ مع الموقف العصيب فيتخفف من نوتره وقلقه ويستعيد بندي

$$
\text { التوازن أو التكامل الذي كان به (sarafino:p.74:1994). }
$$

الضغط التفسي: تجربة ذاتية تحدث اختلالا نفسيا أو عضويا لدى الفرد، و ينتج عن عوامل

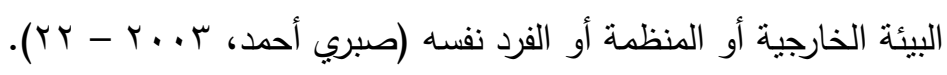

الضغوط النفسية: هي مجموعة من التفاعلات بين الفرد و بيئته و التي تسببت في حالة

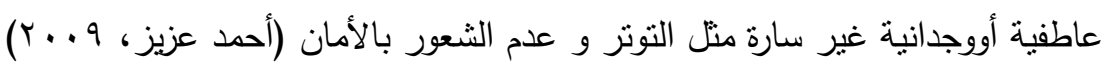
الضغوط البيئية: مجموعة من الظروف الخارجية والمتغيرات البيئية المحيطة بالفرد في بالئي لحظة ما والتي تؤئر على سلوكه في تلاك اللحظة يمكن قياسه قبل ان يوجد بيئة سيكولوجية

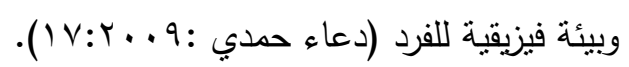

السرطان: هو مرض يصيب الخلايا، التي تعتبر الوحدة الأساسية في بناء الجسم. تقوم

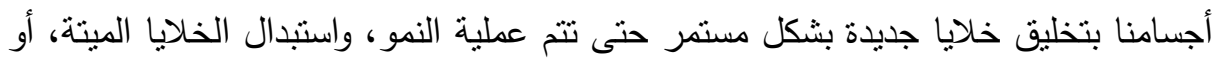

لمعالجة الخلايا التالفة بعد الإصابة بجروح. (Languages-cancer council.com)

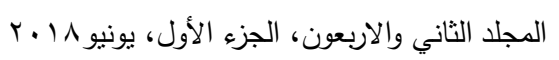


سرطان الرحم: وهو في مرحلة متأخرة على شكل إفرازات مهبلية و نزيف خارج الدورة الثهرية، أو بعد اتصال هو عبارة عن تكاثر و انقسام عشوائي للخلايا الرحمية مكونا

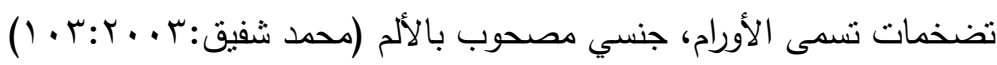

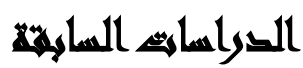

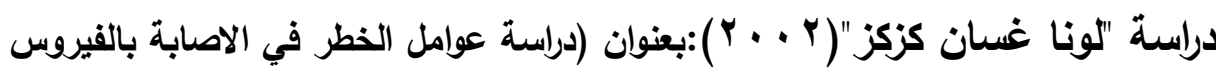
الحليمومي البشري(HPV) في دار التوليد الجامعي ) بهدف الكثف عن وجود فيروس HPV وتوصلت الدراسة لتحديد عوامل الخطورة وهي (إصابة مرافقة بداء منتقل بالجنس - التذخين جهاز مناعي ضعيف - قصة عائلية لسرطان الرحم - العمر - القصة الجنسية والانجابية عوامل ذكرية - تتاول الحبوب الفموية المانعة للحمل - الحالة الاقتصادية والاجتماعية). دراسة "اسماء عبل السلام"(^ . . †): تهدف الدراسة ال توصيف خصائص الاورام النسائية السرطانية في دار التوليد الجامعي والممارسات الطبية، في كلية الطب دمثق. واشتملت عينه الدراسه على (T؟)حالة مقسمه على النحو التالي (Y) (Y)حالة سرطان عنق الرحم، و (1 ( )حالة سرطان مبيض، و و (V) حالات باطن الرحم. وأوضحت النتائج ان سرطان عنق الرحم لايزال يحتل المرتبة الاولى بين الاورام النسائية

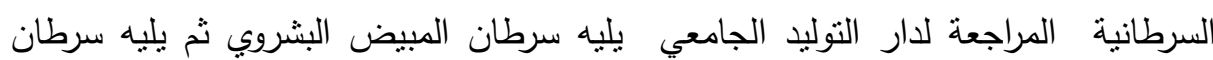
باطن الرحم، وان متوسط العمر عند حدوث المرض منخفض مقارنة بالدول الصناعيه، وراجعت وشخصت العديد من الحالات في المسنتفى واول مرة في مراحل متأخرة من الورم ولم

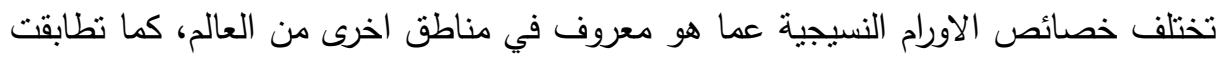

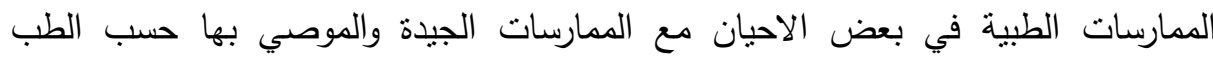
المسند. الا ان هناك قصورا احيانا في دراسة العوامل الانذارية بشكل دقيق، وكذلك هناك قصور في نظام السجلات والمتابعة للمريضات بعد تلقى العلاج. 


\section{(Gorlero, et al.,( 2008):}

هدفت الدراسة الي التعرف إلى الفروق بين عينتين من السيدات مستأصلات الرحم، الأولى:

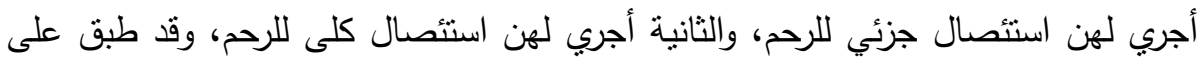
العينتين

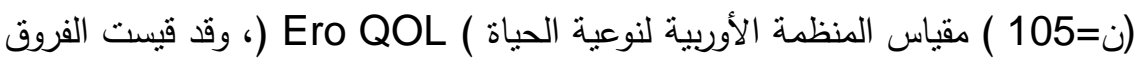

بين العينتين قبل أسبوعين من إجراء الجراحة، وبعد عام من إتمام الاستئصال ،وقد بينت لتوعانه

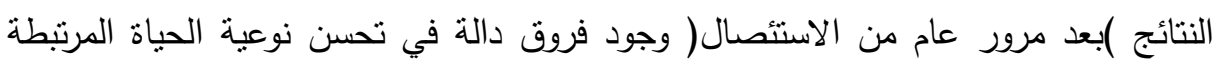
بالصحة لصالح عينة الاستئصال.

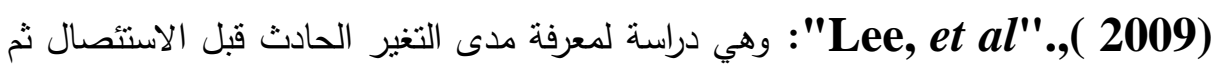
بعده، ثم بعد مرور شهرين، ثم بعد ستة أشهر، وبعد ثمانية أثنهر، في نوعية الحياة

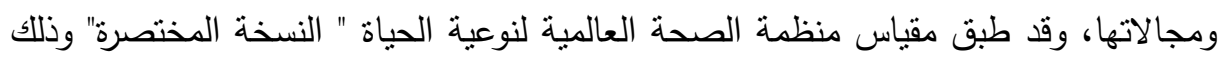

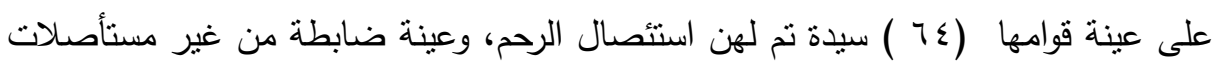

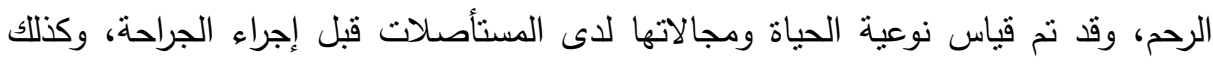
بالنسبة لعينة غير المستأصلات، وقد كثفت النتائج عن وجود فروق دالة لـألة لصالح عينة غير المستأصلات في نوعية الحياة ومجالاتها، وهى فروق كدت على تردى نوعية حياة مستأصلات

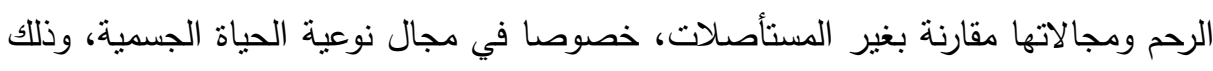

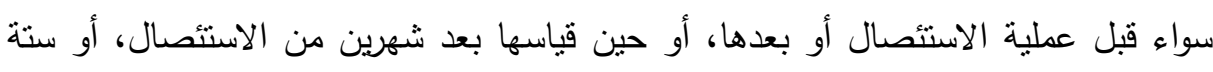
أثنهر أو ثمانية أشثر .

دراسة "علي السيا فهمي"( • ( • ب): بعنوان نوعية الحياة وعلاقتها بالصلابة النفسية لاي عينة من مستأصلات الثي والرحم هافت هذه الدراسة الى معرفة نوعية الحياة والحالة النفسية لدى مستأصلات الثي والرحم

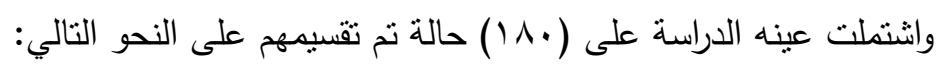

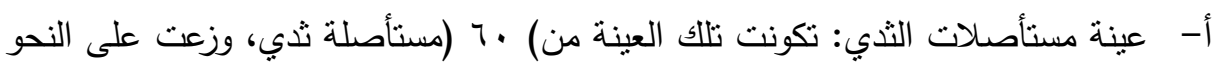


ب- عينة مستأصلات ثدي واحد، (ن) 30 =سيدة .ب -عينة مستأصلات ثديين، ن ) 30 =

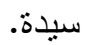
ت- عينة مستأصلات الرحم :تكونت تلك العينة من (90) مستأصلة رحم، وزعت على النحو النالي: - n

ث- عينة مستأصلات رحم جزئي ، (ن ) 30 =سيدة .ب -عينة مستأصلات رحم كلي، ( ن = 30 (ميدة.

ج- عينة مستأصلات رحم شامل" جذري"، ن ) 30 =سيدة. عينة السويات قوامها (30 ) سيدة من غير مستأصلات للثبي أو الرحم، ولا تعاني من الإصابة بأية أورام حميدة أو أو أو

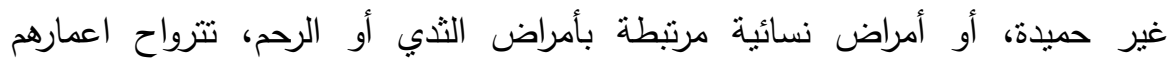

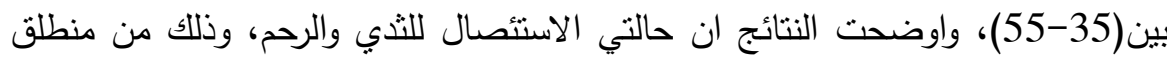

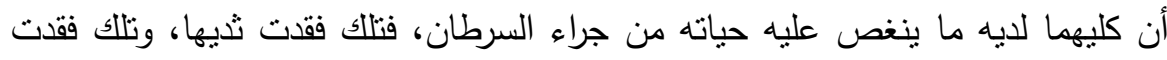

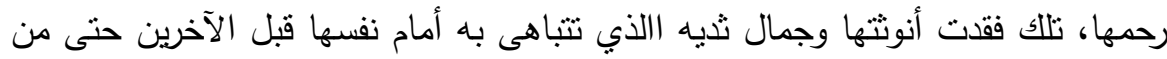

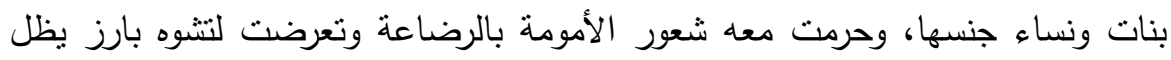

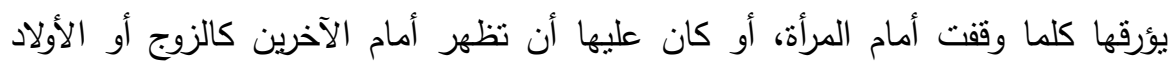

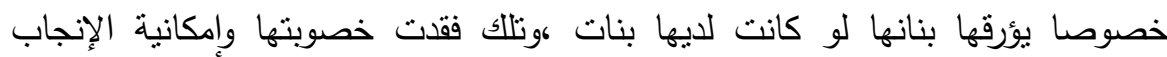
وإسعاد الزوج وزيادة النسل والذ رية، وتحقيق مكانة جيدة في قلب زوجها لونات عندما تكون

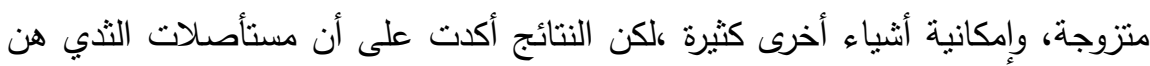

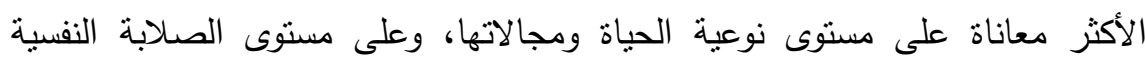
وأبعادها. التعقيب على الدراسات السابقة: من خلال عرضنا للاراسات السابقة نستخلص ما يلي: • تركيز الدراسات فى الغالب على دراسة سرطان الثذي مثل دراسة "لوفير" وزملاؤه V...

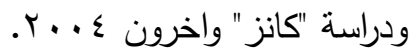
ققلة الدراسات العربية مقارنة بالدراسات الاجنبية، التى تتاولت مرضى الاورام السرطانية من حيث دراسة الضغوط النفسية وكذلك الضغوط البيئية. 
• اعتماد معظم هذه الدراسات على استخدام ادوات القياس مثل المقابلة والاستيان كونها من

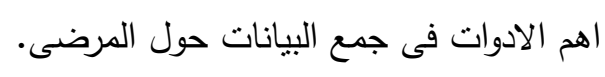

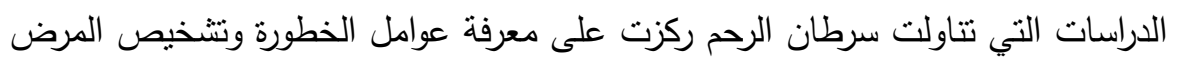

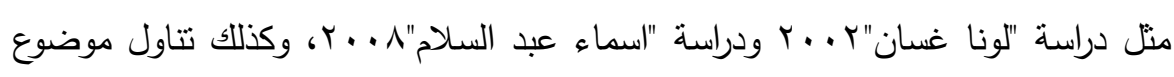

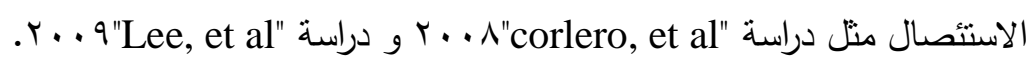

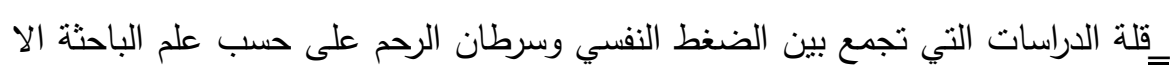

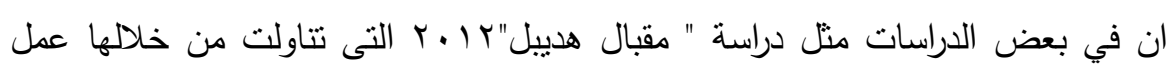

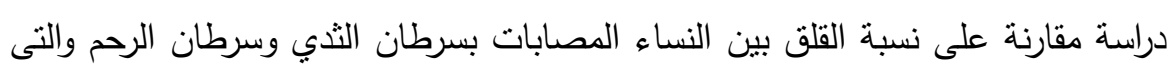

اوضحت نتائجها ان النساء المصابات بسرطان الرحم نسبة القلق لديهم مرتفعة .

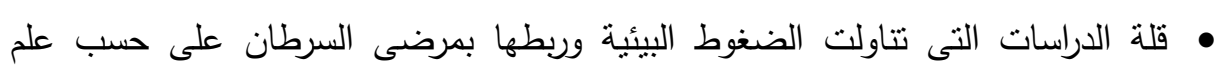
الباحثة.

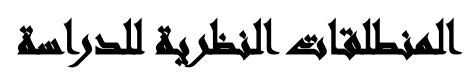

النظريات المفسرة للضغط النفسي: لقد تعددت النظريات التي وضعت لتفسير الضغوط النفسية لدى الافراد، وعلى الرغم من انتراكها في المضمون النظري إلا أنها اختلفت في الاتجاه الذي سلكته كل نظرية. • نظريتسيلي هانز:Hans Sely:) الذي شرح في كتابه ضغوط الحياة الذي ألفه في عام 1907 عندما كان طالبا في كلية

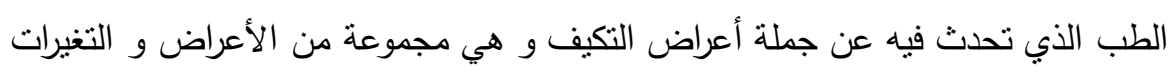
التي تحدث عندما يتعرض الكائن الحي لضغوط شديدة من أجل تحقيق نوع من التوافق بين الكائن البيئة الضاغطة. وتتطلق نظرية (هانز سيلي) من مسلمه نرى ان الضغط النفسي متغير غير مستقل، وهو

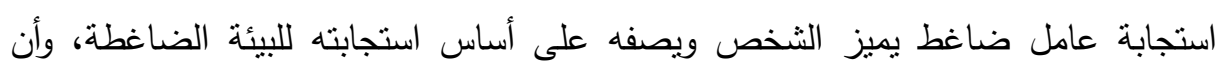

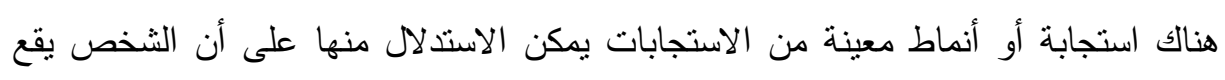


تحت تأثنر بيئي مزعج، ويعتبر" سيلي "أن أعراض الاستجابة الفيزيولوجية للضاغط عالمية، وهدفها هو المحافظة على الكيان والحياة. (sarafino:p.74:1994) وفي صدد الدفاع ضد الضغط حدد" سيلي "ثلاث مراحل تمثل عنده مراحل التكيف العام وهي: • مرطلة الانذار (الفزع): وفيه نظهر تغييرات واستجابات تتميز بها درجة التعرض المبدئي

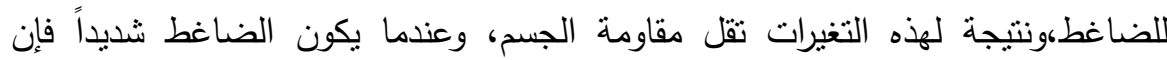
مقاومة الجسم تتهار وتحدث الوفاة. • مرحلة المقاومة: وتحدث هذه المرحلة حين يكون التعرض للضاغط متلازماً مع التكيف عندها تختفي التغيرات التي ظهرت على الجسم في المرحلة الأولى وتظهر تغيرات

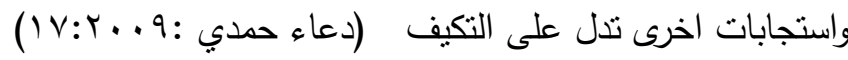
• مرحلة الإجهاد:وهي المرحلة التي تعقب مرحلة المقاومة ويكون فيها الجسم قد تكيف غير أن الطاقة الضرورية تكون قد استتفذت وإذا كانت الاستجابات الدفاعية شديدة ومستمرة لفترة طويلة قد ينتج عنها أم ا رض التكيف، وقد أوضح كل من" لفين "و"أوسكونش "أن "سيلي" قد وضع رسماً توضيحياً لنظريته.

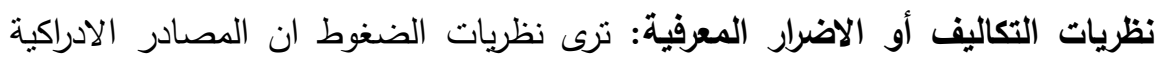
والمعرفية المخصصة لمهام اخرى ويسمى هذا الاسلوب بافتراض التكاليف المعرفية (Glass\&Singer 1973).Cognitive Costs hypothesis يرى اصحاب هذه النظرية ان الحدث الضاغط يتطلب من الفرد استهلاك مصادره المعرفية للتغلب عليه وعلى الفرد ان يفهم ماهو الحدث الضاغط والى مدى سيسوء الحال وهل سيكون الحدث الضاغط مستمرا ام لا. وتلك الجهود كمتذب المصادر الادراكية والمعرفية للفرد بعيدا عن المهام الاخرى فى الحياة، ومن ثم يتنقى له القليل من الوقت والطاقة للتركيز

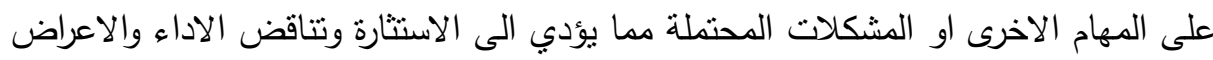
الاخرى للضغوط لان الفرد يكون مضطرا لمراقبة البيئة باستمرار بحثنا عن المثيرات المهددة

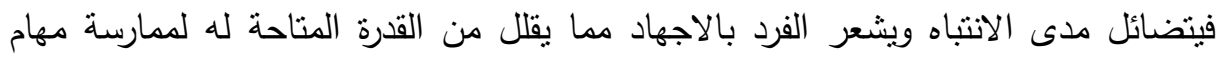
اخرى ـ ان تحليل التكاليف المعرفية للضغوط تدعمه حقيقة ان الاحداث غير القابلة للتتبؤ وغير القابلة للسيطرة اكثر ضغطا من الاحداث القابلة للسيطرة والتنبؤ، ومن المفترض ان الفرد 256

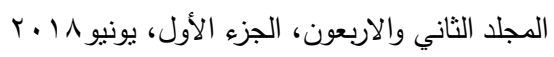


يكون مطلوبا منه بذل قدر من الجهد المعرفي حين يكون الحدث الضاغط قابلا للتتبؤ وقابلا للسيطرة اقل مما لو لم يكن قابلا للتنبؤ والسيطرة لان الفرد لايكون متحفزا لنرقيب امكانية التهديد.

نظريات الاداء الانفعالي: Theories of Emotional Functioning: حيث تعطي هذه النظريات للاستجابات الانفعاليه دورا مركزا، حيث ان الضغوط تؤدي الى الإنيات الاحباط

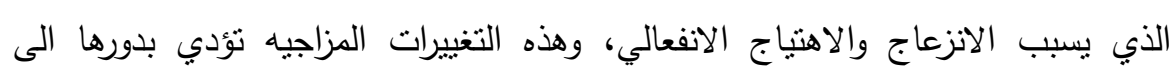

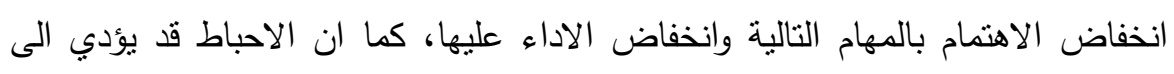

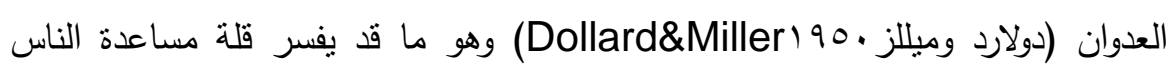

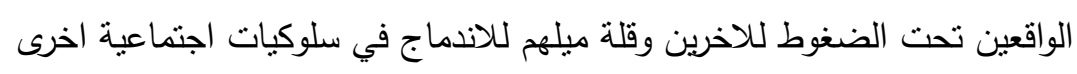
(كوهن Cohen1980) ولكن التفسير القائم على الاداء الانفعالي قد ينطبق على انواع معينة من الضغوط: اولا: ليست كل الضغوط تؤدي الى حالة مزاجية سلبية ومع ذلك فإننا نلاحظ انخفاض الدافعية وانخفاض الاداء. ثنانيا: ان الضغوط لاتؤدي دوما الا الانزعاج فإنها قد نؤدي الى الخوف والاكتئاب وحالات مزاجية اخرى لا تقلل الدافعية ولا تخفض الاداء.

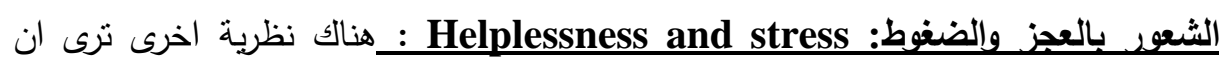
الضغوط تؤدي الى الشعور بالعجز وانعدام الحيلة وان ذلك الثعور يلعب دورا مركزيا في

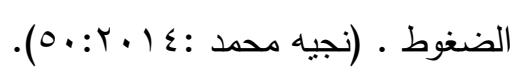

\section{إجبراعاهت التواسمة}

تتنمي هذه الدراسة إلى نمط الدراسات الوصفية لكونها أنسب أنواع الدراسات ملائمة

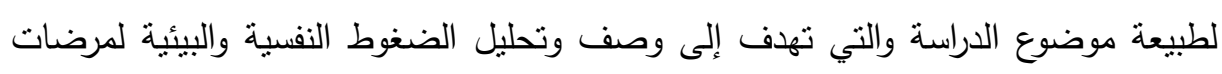

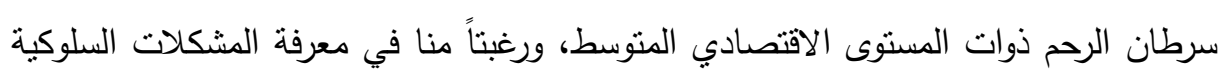

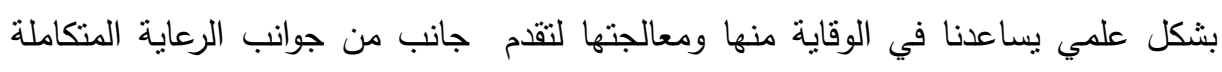

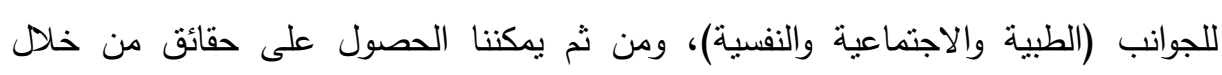

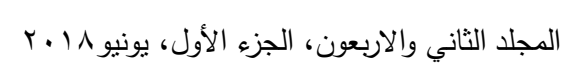


المعلومات وتفسيرها ثم استخلاص النتائج ووضع المؤشرات التي تساعد في الحد من الضغوط النفسية والبيئية لمريضات سرطان الرحم.

\section{هنهمج التوراسة}

منهج المسح الاجتماعي بالعينة في سبيل تحقيق هدف الدراسة واختبار فروضها،

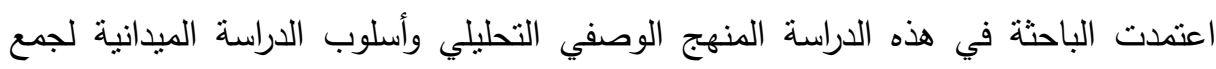
المعلومات والبيانات اللازمة لإتمام الدراسة.

أما مصدر البيانات فقد تم الحصول عليها من مصدرين هما:

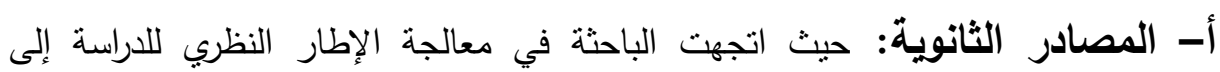
مصادر البيانات الثانوية والتي تتمثل في الكتب والمراجع العربية والأجنبية ذات العلاقة، والدوريات والمقالات والتقارير ، والأبحاث والدراسات السابقة التي تتاولت موضوع الدارسة،

$$
\text { والبحث والمطالعة في مواقع الإنترنت المختلفة. }
$$

ب- المصادر الأولية: وتتمتل في جمع البيانات الأولية ميدانياً، وذلك من خلال استخدام

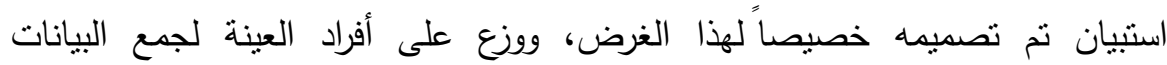

$$
\text { المطلوبة. }
$$

ميدان الاراسة: تم إجراء هذه الدراسة على السيدات المريضات بسرطان الرحم.

\section{أسوايت التواسم}

- - استبيان (من اعداد الباحثة).

- مقياس الضغوط النفسية والبيئية لمريضات سرطان الرحم (اعداد الباحثة).

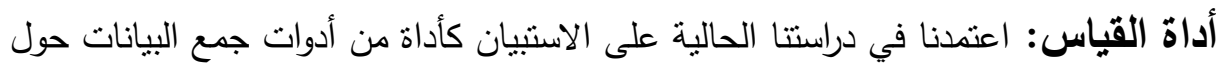
الدراسة لذا يعرف الاستنيان على أنه مجموعة من الأسئلة المكتوبة التي توضع بقصد

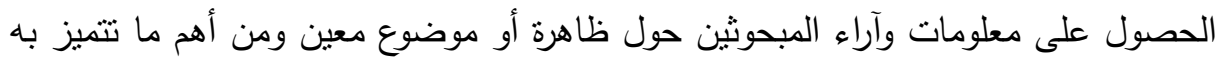
الاستبانة هو توفير الكثير من الوقت والجها على الباحث، وعلى هذا الأساس تم تصميم 
مقياس خاص بموضوع الدراسة مصمم من قبل الباحث وذللك من أجل جمع البيانات والمعلومات الخاصة التحديات الاجتماعية والفيزيقية التي تواجه استخدام المرأة للتكنولوجيا الحديثة.

كما يتكون هذا المقياس من شقين الثق الأول يتضمن البنود الخاصة بالتحديات الاجتماعية والفيزيقية ويبلغ عدد بنوده •ـ بند والثق الثاني يتضمن البنود الخاصة باستخدام التكنولوجيا الحديثة ويبلغ عدد بنوده . r بند. أما البدائل التي نم استعمالها في كلا الثقين فهي بدائل واحدة وهي بـ بلدئل بدائل: نعم، أحيانا،

صدق وثبات ادوات الدراسة: ويشمل وصف أداة الدراسة علي صدق الاتساق الظاهري وثبات وصدق الاتساق الداخلي لأداة الدراسة وذلك على النحو التالي وصلي:

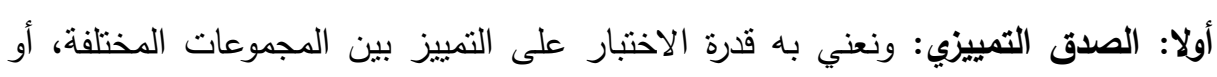
حتى الأفراد التي تقع درجاتهم على طرفي المنحنى. نتائج الصدق التمييزي: لسحاب القوة التمييزية رنبت الدرجات التئي الكلية التي حصل عليها من

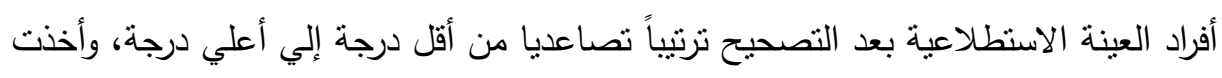

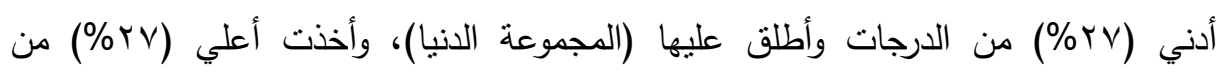
الدرجات وأطلق عليها (المجموعة العليا)، وقد اعتدت البات الباحثة على طريقة المجموعتين المتطرفتين، والجدول رقم (rا') يوضح نتائج هذا الإجراء.

\begin{tabular}{|c|c|c|c|c|c|c|c|}
\hline الاستدلال & مسلادة Tي & قيمة t & الحريةة Df & الانحراف & المتوسط & العدد & المستويات \\
\hline \multirow{2}{*}{ دالة } & \multirow{2}{*}{$\cdot, \cdots$} & \multirow{2}{*}{$q, r \times q-$} & \multirow{2}{*}{1.} & $\cdot, 7 \Lambda \cdot V \vee$ & $r, \wedge 0 \ldots$ & 7 & الدنبا VYrعة \\
\hline & & & &., .940. & $0,\{77 \vee$ & 7 & $\begin{array}{l}\text { العليا VYموعة } \\
\text { \% }\end{array}$ \\
\hline
\end{tabular}

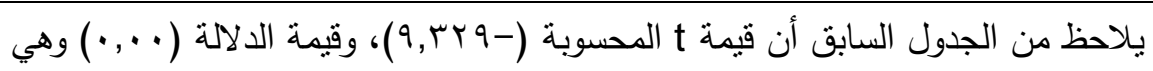
دالة عند ا +, ..، مما يثير إلى أن للمقياس قدرة على التمبيز بين طرفيه.

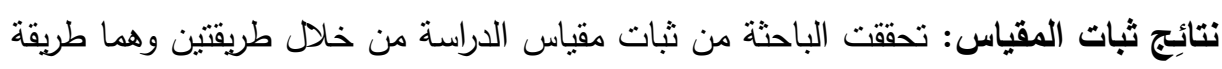
التجزئة النصفية ومعامل ألفا كرونباخ.

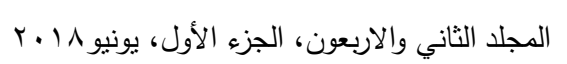


أولاً: طريقة التجزئة النصفية: Split-Half Coefficient method: تم استخدام درجات العينة الاسنطلاعية لحساب ثبات المقياس بطريقة التجزئة النصفية، حيث احتسبت درجة النصف الأول لكل بعد من أبعاد المقياس وكذلك درجة النصف الثاني من الدرجات وذللك لحساب معامل الارتباط بين النصفين ثم جري تعديل الطول باستخدام معادلة سبيرمان

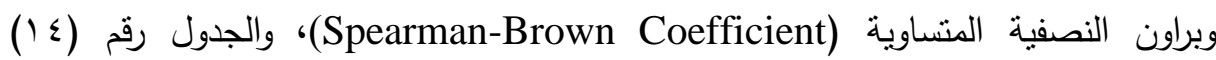
يوضح ذللك.

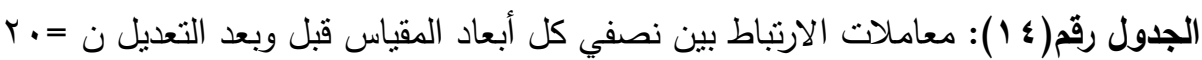

\begin{tabular}{|c|c|c|c|c|c|}
\hline معامل الثبات & الارتباط قبل & العبارات & \multicolumn{2}{|c|}{ الأبعاد } & r \\
\hline$\cdot, 9 \wedge \varepsilon$ & $\cdot, 971$ & rt & \multicolumn{2}{|c|}{ الضغوط النفسية } & 1 \\
\hline$\cdot, \wedge \vee \wedge$ & $\cdot, \nabla \wedge \mu$ & 1. & \multicolumn{2}{|c|}{ الضغوط الاقتصادية } & $r$ \\
\hline$\cdot, 979$ & $\cdot, 9 \leqslant$. & $1 \cdot$ & مجال بيئة المسكن & \multirow{2}{*}{ الضيغوطة } & \multirow{2}{*}{ r } \\
\hline$\cdot 9 \leq 1$ & $\cdot, \wedge \wedge \wedge$ & $\wedge$ & مجال بيئة العمل & & \\
\hline$\cdot, 97 \wedge$ & $\cdot, 9 \pi \wedge$ & 7. & \multicolumn{3}{|c|}{ إجمالي ابعاد المقياس } \\
\hline
\end{tabular}

بتضح من الجدول السابق رقم (ع ا) أن معامل الثابت الكلي للمقياس (1^97, •) وهذا يدل على أن ابعاد المقياس تتمتع بدرجة عالية جدا من الثبات تطمئن الباحثة إلى تطبيقه على

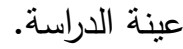

\section{xalyall sint}

شروط اختيار العينة اجراء هذه الدراسة على السيدات المصابات بسرطان الرحم اللاتي يترددن

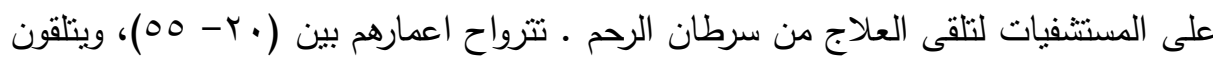
العلاج سواء العلاج الهرموني او العلاج الكيميائي او الاشعاعي، بعد موافقتهم على المشاركة في الدراسة. خصائص عينة الاراسة بعد التحقق من صدق أداة القباس وثباتها، وزعت الاستمارات على

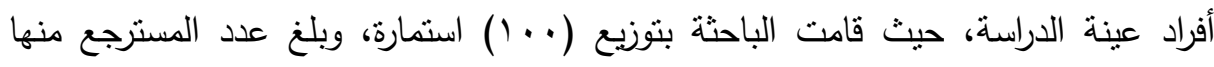
(^) (استمارة، منهم (ع () استمارة غير صالحة للتحليل الإحصائي، وبالتالي تكونت العينة

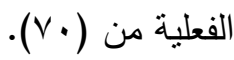


فيما يلي عرض لعينة الاراسة وفق الخصائص الديموغرافية جدول رقم(1 ): يوضح نوزيع افراد العينة حسب متغير سن اكتشاف المرض لئل

\begin{tabular}{|c|c|c|}
\hline النسبة المئوية \% & العدد & اكتثاف المرض \\
\hline$\%$ \% & IV & اقل من وب سنة \\
\hline$\% r \varepsilon, r$ & $T \xi$ & 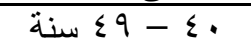 \\
\hline$\%{ }^{\prime} \cdot, \cdot \cdot$ & YI & . 09 - 09 . \\
\hline$\% \backslash 1, \varepsilon$ & $\Lambda$ & أعلى من · 7 سنة \\
\hline$\% 1 \ldots$ & $V \cdot$ & الإجمالى \\
\hline
\end{tabular}

من خلال استعراض الجدول رقم (1) الخاص بتوزيع أفراد عينة الدراسة حسب متغير

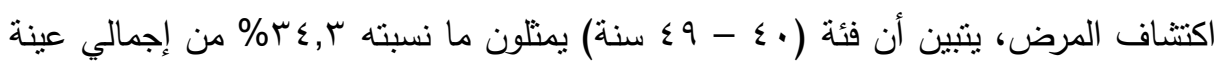

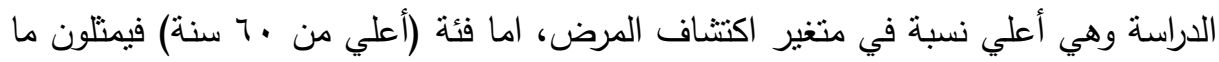
نسبته ع, 11 1\% من إجمالي عينة الدراسة وهي أقل نسبة في متغير اكتشاف المرض.

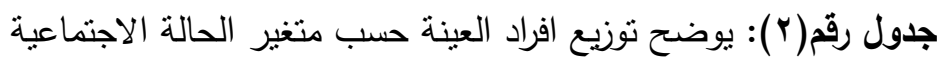

\begin{tabular}{|c|c|c|}
\hline النسبة المئوية \% & العدد & الحالة الاجتماعية \\
\hline$\%$ & 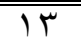 & أَنسة \\
\hline$\% \circ r, \wedge$ & $\overline{T V}$ & متزوجة \\
\hline$\% \backslash 0, V$ & 11 & مطلقة \\
\hline$\% \backslash r, 9$ & 9 & أرملة \\
\hline$\% 1 \ldots$ & $\mathrm{V} \cdot$ & الإجمالى \\
\hline
\end{tabular}

من خلال استعراض الجدول رقم (r) الخاص بتوزيع أفراد عينة الدراسة حسب متغير

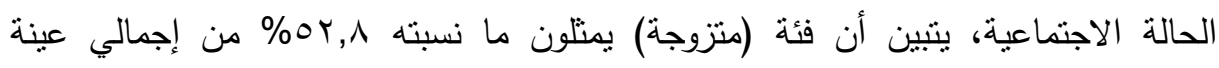

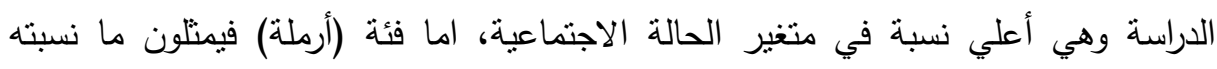

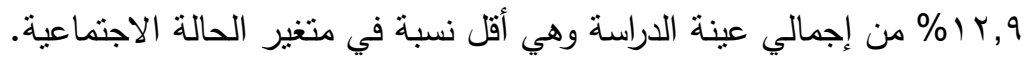

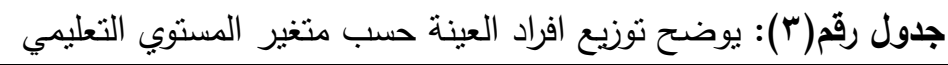

\begin{tabular}{|c|c|c|}
\hline النسبة المئوية \% & 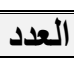 & المستوي التعليمى \\
\hline \%०V,1 & $\varepsilon$. & (عالم \\
\hline$\% r v, 1$ & 19 & متوسط \\
\hline$\% 10, \wedge$ & 11 & لا بوجد \\
\hline$\% 1 \ldots$ & $V$. & الإجمالي \\
\hline
\end{tabular}


من خلال استعراض الجدول رقم (r) الخاص بتوزيع أفراد عينة الدراسة حسب متغير

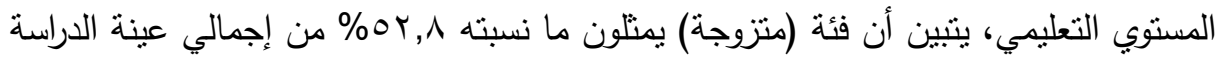

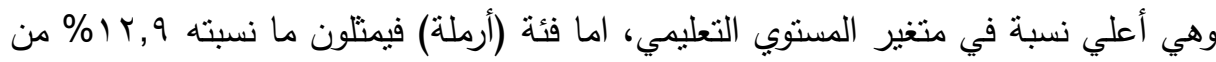
إجمالي عينة الدراسة وهي أقل نسبة في متغير المستوي التعليمي.

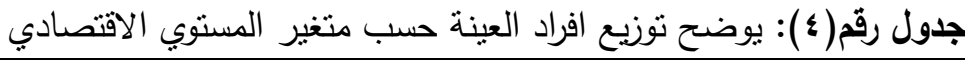

\begin{tabular}{|c|c|c|}
\hline النسبة المئوية \% & العدد إل العد & المستوي الاقتّادي \\
\hline \% \% & $1 \leqslant$ & جيد \\
\hline$\% 0 .$, & ro & متوسط \\
\hline$\%{ }^{\prime} \cdot, \cdot$ & YI & ضعيف \\
\hline$\% 1 \ldots$ & $V$. & الإجمالى \\
\hline
\end{tabular}

من خلال استعراض الجدول رقم (ع) الخاص بتوزيع أفراد عينة الدراسة حسب متغير

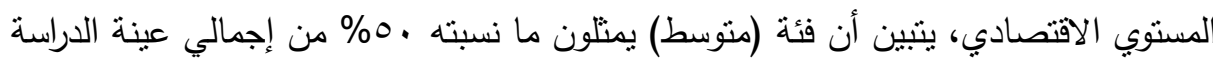

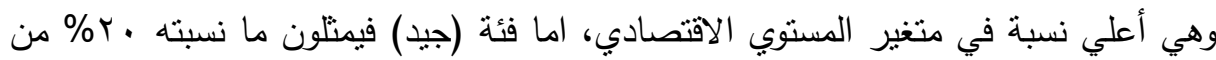
إجمالي عينة الدراسة وهي أقل نسبة في متغير المستوي الاقتصادي.

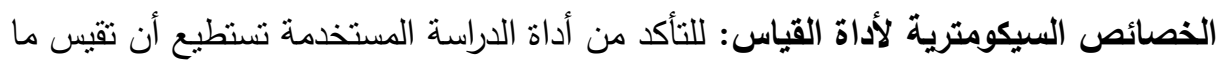

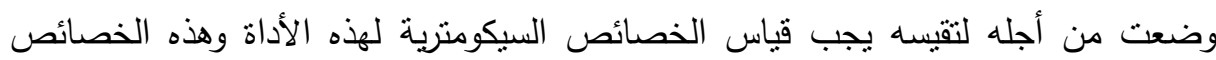
تتمتل في الصدق والثبات وسنتطرق إلى كيفية حساب كل خاصية من هاتين الخاصيتين. عبنة الدراسة بعد التحقق من صدق أداة القياس وثباتها، وزعت الاستمارات على أفراد

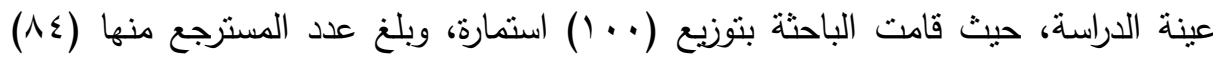
استمارة، منهم (ع () استمارة غير صالحة للتحليل الإحصائي، وبالتالي تكونت العينة الفعلية

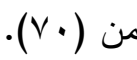
تصميم أداة الاراسة: قامت الباحثة بتصميم استبيان لمعرفة البيانات الاولية ومقياس الضغوط

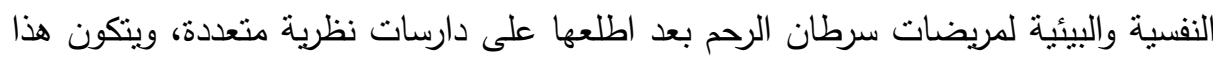

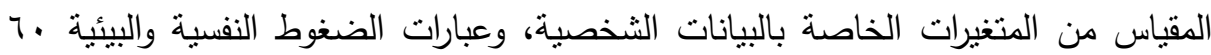
عبارة مقسمة على ثناث أبعاد. أما البدائل التي نم استعمالها في فهي بدائل واحدة وهي بـ بدائل: نعم، محايد، لا. 


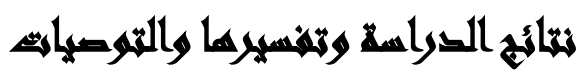

الفرض الأول: توجد علاقة معنوية ذات دلالة إحصائية إيجابية بين اورام سرطان الرحم ويين الضغوط النفسية.

وقد تطلب اختبار هذا الفرض، حساب المتوسط الفرضي لبعد (الضغوط النفسية)، حيث

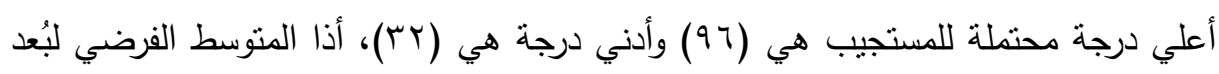

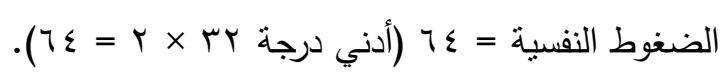

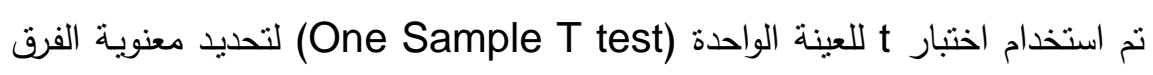
بين متوسطات استجابات أفراد العينة، وتكون عبارات البعد إيجابية بمعني أن أفراد العينة

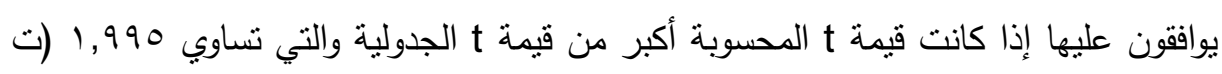

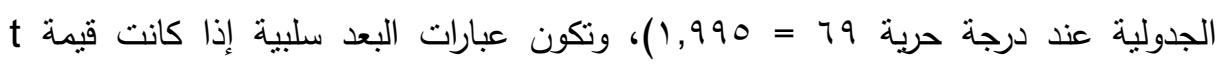

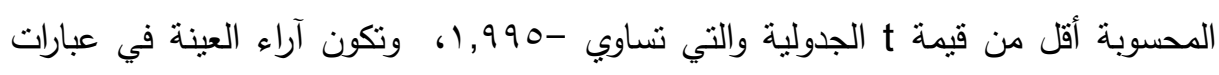

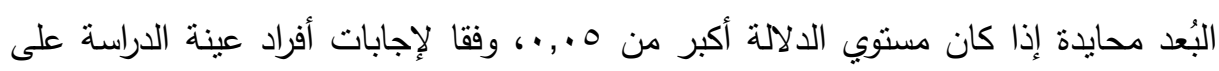
العبارات الواردة في البعد.

جدول رقم(1) : يوضح نتائج اختبار t فيما يتعلق باختبار الفرضية الأولي

\begin{tabular}{|c|c|c|c|c|c|c|c|}
\hline الدستوي & الدرجة & قالجدولية & قالمسموية & الفرضيط & الانحراف & المتوسط & البعد \\
\hline$\cdot, \cdots$ & 79 & 1,990 & $\Lambda, 1 \vee \neg$ & $7 \varepsilon$ & 11,104 & $V \leqslant, 10 \pi$ & الضفنوبة \\
\hline
\end{tabular}

من خلال نتائج الجدول السابق (1) نجد أن هناك علاقة معنوية ايجابية بين اورام

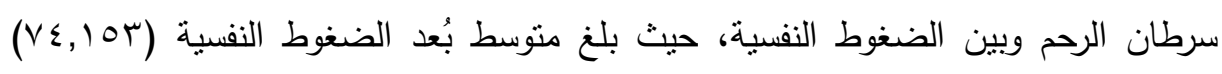

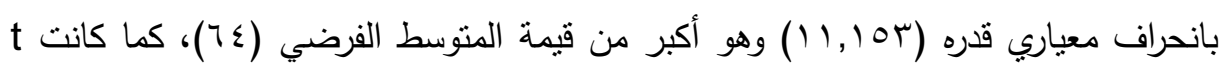

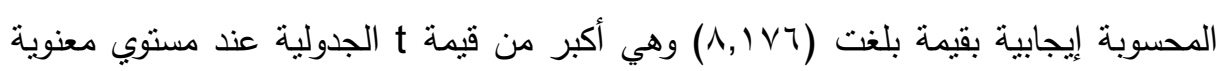
(0. . •)، وهذا يؤكد صحة قبول الفرضية التي تتص على أنه: توجد علاقة معنوية ذات دلالة إحصائية إيجابية بين اورام سرطان الرحم وبين الضغوط النغول النفسية. 


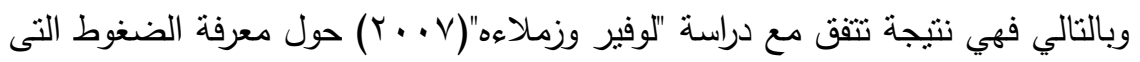

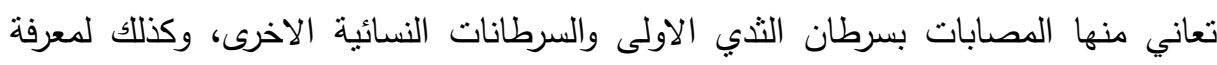

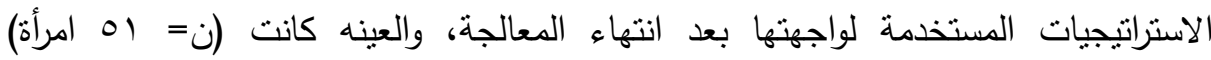

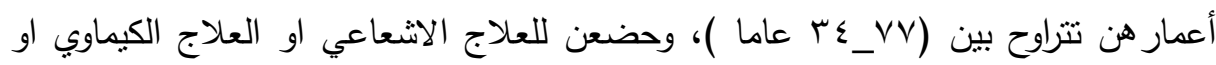

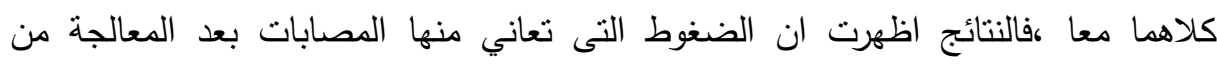
السرطان تتضمن : الثعور بالثكك وعدم الثقة بالمعالجة والمتابعة الطبية والاعراض المرضية،

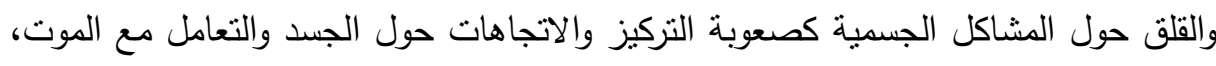
المشاركات فى الدراسة استخدمن اسلوب التقبل والتدين واللهو والتسلية كإستراتيجيات اولية

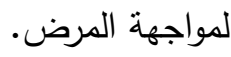
ويمكن تفسير ذلك إلى أن مريض السرطان يمر بعدة أزمات نفسية تؤثر فيها عدة

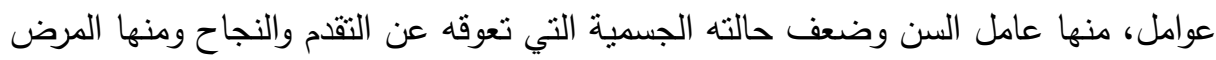
والذي يكون سبابا في ضعف الإ ا ردة والمقاومة والتي غالبا ما نظهر في الثعور بالتعب لهن

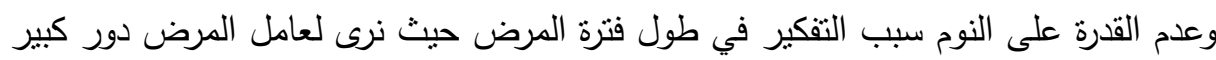
في نشوء القلق وارتفاع معدلاته.

وكذلك يمكن تفسير الضغوط النفسية لمريضة سرطان الرحم من خلال نظرية "سيلي"sely يرى سيلي أن الانفعالات المصاحبة للانعصاب منل الخوف والقلق والاكتئاب

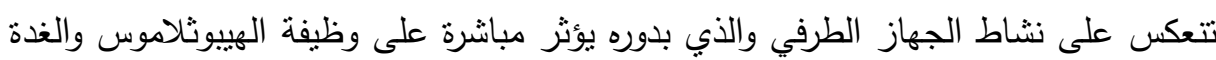
النخامية، حيث إن هذه الغذة هي المهيمنة على عمل الجهاز الغدي للجسم فإن خلل هذه الغذة الرئيسية سوف يؤدي بالضرورة إلى اضطراب عام في النشاط الغدي الهرموني، وهي ضمن فهن ملاحظاته لدى كثير من مرضى السرطان حيث يلاحظ وجود خلل في نشاط الغدد بطريقة متكررة وترنبط مع الإصابة بالأورام الخبيثة. 
الفرض الثاني: توجد علاقة معنوية ذات دلالة إحصائية ايجابية بين اورام سرطان الرحم

وبين الضغوط البيئية.

وقد تطلب اختبار هذا الفرض، حساب المتوسط الفرضي لبُعد (الضغوط الاقتصادية)،

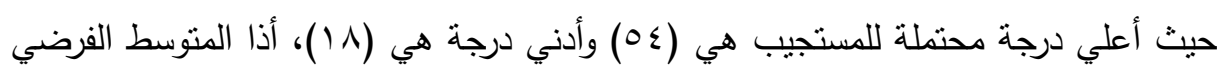

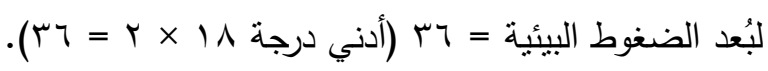
وقد نم استخدام اختبار t للعينة الواحدة (One Sample T test) لتحديد معنوية الفرق بين متوسطات استجابات أفراد العينة كما بينا سابقاً.

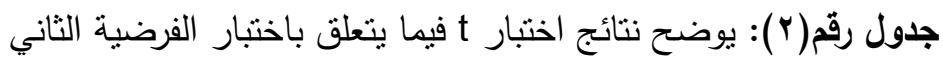

\begin{tabular}{|c|c|c|c|c|c|c|c|}
\hline الدلائةي & الدرجة & قالجدولية & المحسيمة t & الفرضيط & الانحراف & المتوسط & البعد \\
\hline$\cdot, \cdots$ & 79 & 1,990 & $1 \cdot, 7 \leqslant 1$ & Tr & $7, V Y V$ & $\varepsilon \varepsilon, 00 \mathrm{~V}$ & الضئغوط \\
\hline
\end{tabular}

من خلال نتائج الجدول السابق (Y) نجد أن هناك علاقة معنوية ايجابية بين اورام

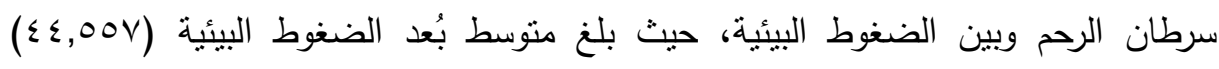
بانحراف معياري قدره (T,VYV

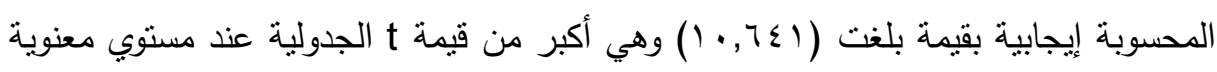
(0 . , •)، وهذا يؤكد صحة قبول الفرضية التي تتص على أنه: توجد علاقة معنوية ذات دلالة النة

إحصائية ايجابية بين اورام سرطان الرحم وبين الضغوط البئية ولئية.

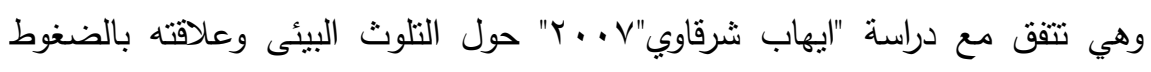

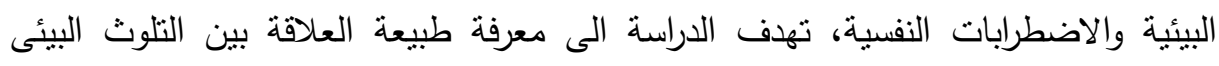

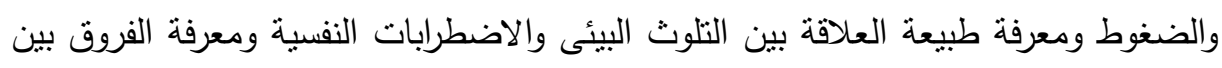

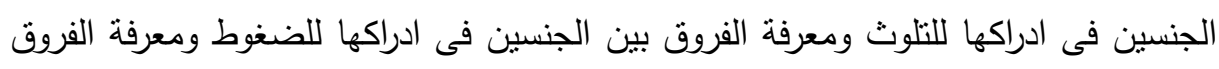

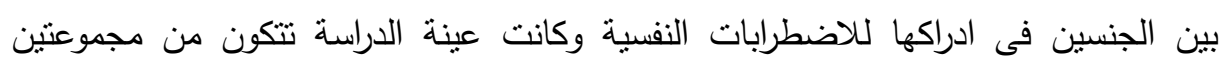

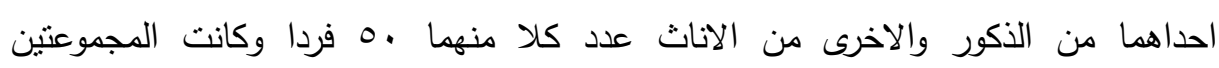

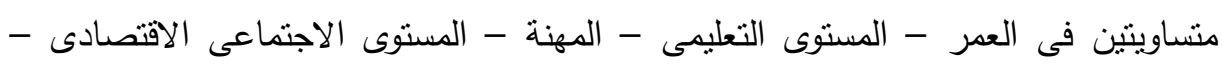

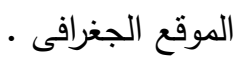


توصلت الدراسة لهذه النتائج وهى أن توجد علاقة ارتباطية موجبة دالة احصائيا بين

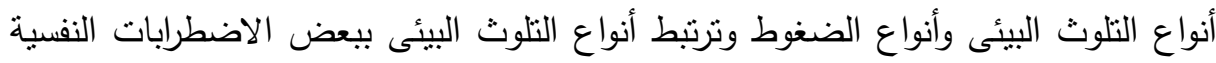

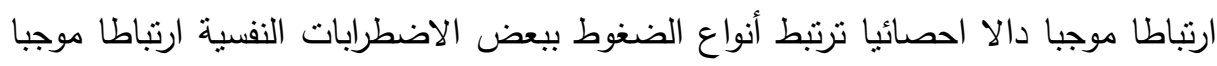

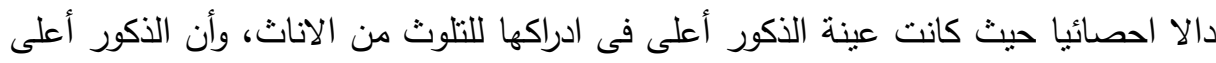

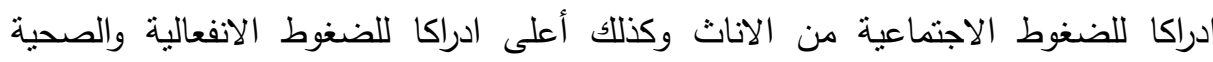
والثخصية .

ويمكن تفسير الضغوط من خلال نظرية "الاستثارة والضغوط" حيث فسرت نظرية

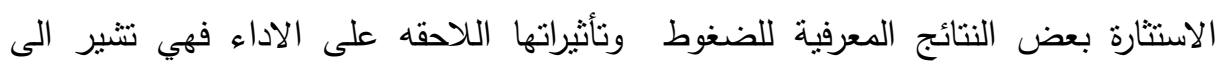
العمليات الفسيولوجية التى قد تؤثر الضغوط على صحة الفرد من خلالها. وهكذا فان نظرية الاستثارة تساهم في الفهم البيولوجي النفسي للضغوط والمرض ولكنها لاتفسر خبرة الضغوط

الفرض الثالث: توجد علاقة معنوية ذات دلاية إحصائية سلبية بين اورام سرطان الرحم

\section{ويبن الضغوط الاقتصادية.}

وقد تطلب اختبار هذا الفرض، حساب المتوسط الفرضي لبُعد (الضغوط الاقتصادية)،

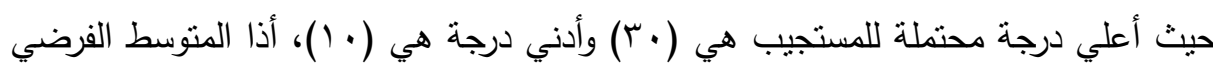

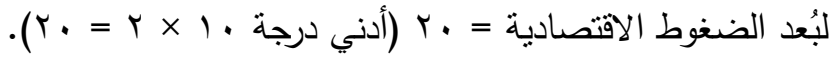

وقد نم استخدام اختبار t للعينة الواحدة (One Sample T test) لتحديد معنوية

الفرق بين متوسطات استجابات أفراد العينة كما بينا سابقاً. جدول رقم(r): يوضح نتائج اختبار t فيما يتعلق باختبار الفرضية الثاني

\begin{tabular}{|c|c|c|c|c|c|c|c|}
\hline مستوي & الحرية & الجدولية & المحسبوية & الفرضي & الانحراف & المتوسط & البعد \\
\hline$\cdot, \cdot, Y r$ & 79 & 1,990 & r,077- & $r$. & 0,971 & $|\wedge,| \vee \mid$ & الاقتصغادية \\
\hline
\end{tabular}


من خلا نتائج الجدول السابق (r) نجد أن هناك علاقة معنوية سلبية بين اورام سرطان

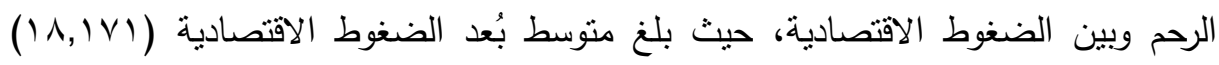

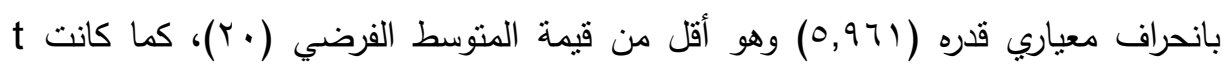

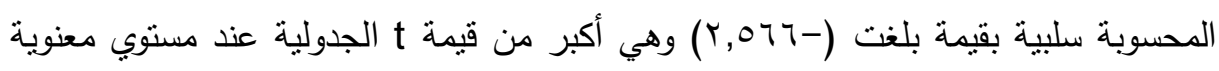
(0. . •)، وهذا يؤكد صحة قبول الفرضية التي تتص على أنه: توجد علاقة معنوية ذات دلالة إحصائية سلبية بين اورام سرطان الرحم وبين الضغوط الاقتصادية.

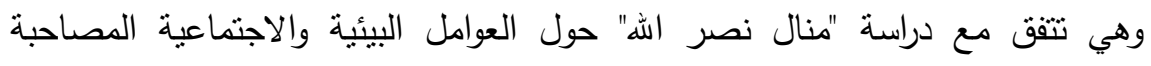

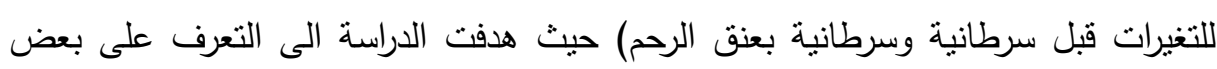
العوامل البيئية المختلفة ومنها السن المبكر فى الزواج وتعدد الزواج وعدد مرات الولادة الونات

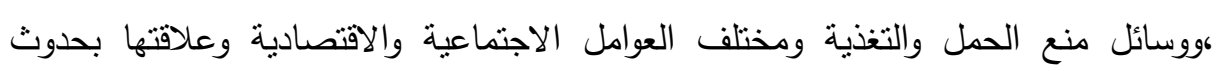
(التشؤات الورميه الخلوية وسرطان عنق الرحم)حيث اجرت هذا البحث علي . . بر سيدة.

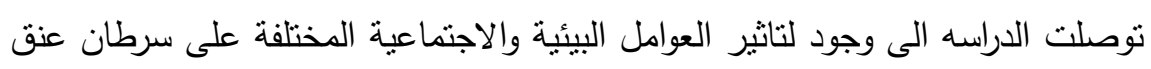
الرحم ومن ابرز هذه العوامل : السن المبكر للزواج مع الحمل المتكرر والاصابة بالتهابات

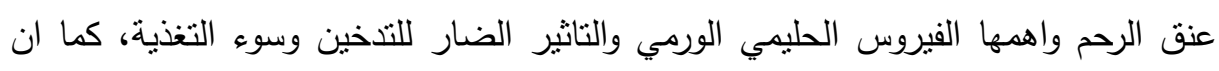

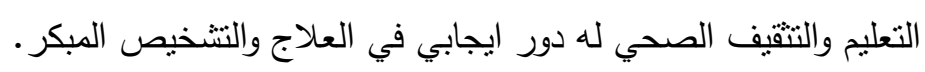

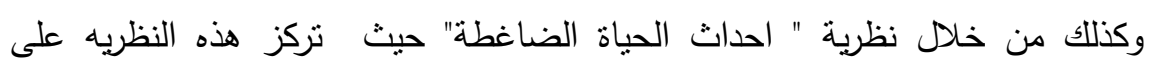

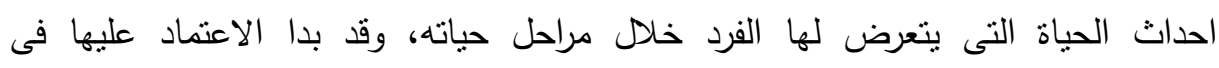
الثلاثثنيات من القرن العشرين، ممثلة في دراسات "ماير" الذي قام باستخدام قوائم خبرات الحياة وضات

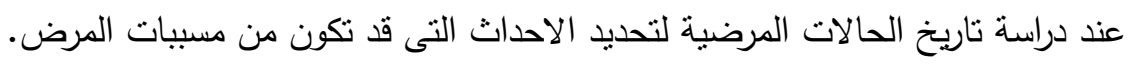

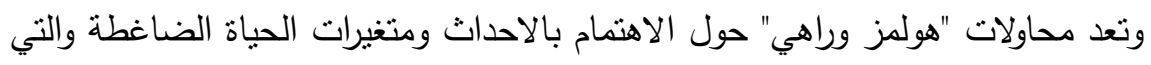
يحتمل ان تكون ذات تأثير على الفرد، فقد ركز على الاحداث التى قد تؤثر على الألى الافراد في

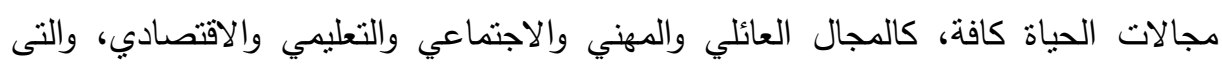

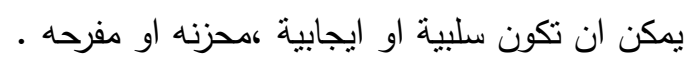


يتميز مريض السرطان بمزاج كئيب وحزين ناتج عن الآلام المصحوبة بالمرض وكذللك

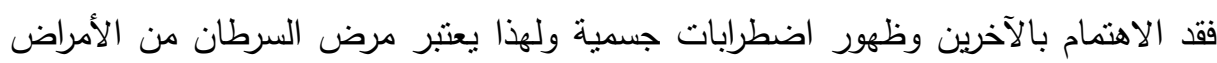
الخطيرة التي يجب علينا الاهتمام والتكفل بها من الجانب النفسي، وكذللك بما قد بلعبه الأخصائي النفسي في مراكز مكافحة السرطان من دور في الاستماع للمرضى والتكفل بهم نفسيا.

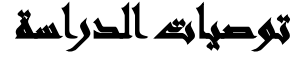

في ضوء إجراءات البحث وما توصلنا إليه من نتائج وما قدمناه من تفسيرات كمية وكيفية نقدم جملة من التوصيات والاقتراحات

• نوسيع مجال علاج الأمراض السرطانية ،وذلك من خلال دمج الرعاية النفسية لمرضى ولفي

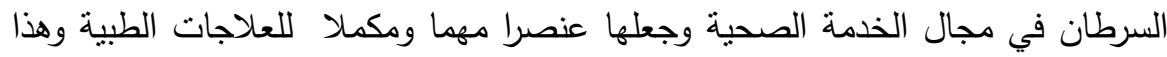
بغرض التخفيف من حدة التوترات الانفعالية والمشاكل النفسية التي قد يتعرض لها المرضى نتيجة الإصابة بمرض السرطان.

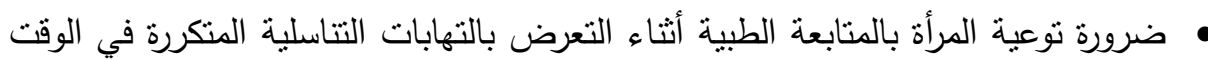
المبكر لتجنب الوقوع في مرض السرطان. زيادة الوعي بمرض سرطان الرحم وخطورته على السيدات في حالة وجود تاريخ مرضي

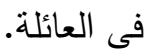

نشر الثقافة الوقائية من مرض سرطان الرحم من خلال الندوات والمحاضرات النقافية.

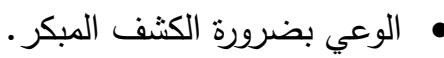

• اهمية المساندة الاجتماعية التى تلعب دورا مها في توافق المريض مع نفسه ومع الآخرين لذا يجب رعاية المريضة من الناحية الاجتماعية . •عمل برامج اعلامية لتوعية السيدات عن كيفية حدوث المرض وكيفية الوقاية منه. • إنشاء مراكز علاجية خاصة بمرض سرطان الرحم وتوفير العلاج لهم • • إجراء دراسات وبحوث حول الضغوط النفسية التى تعاني منها مريضة سرطان الرحم. 


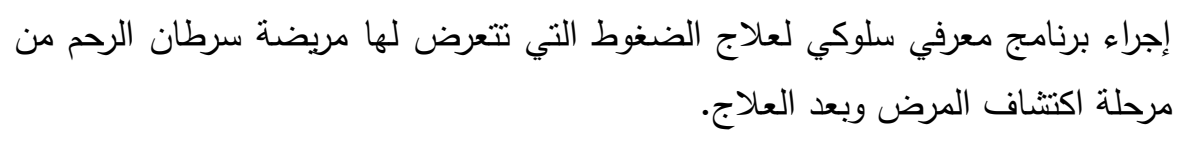

\section{stl}

إبراهيم عبد الستار(991 (1): الاكتئاب ( اضطراب العصر الحديث فهمه واساليب علاجه)،

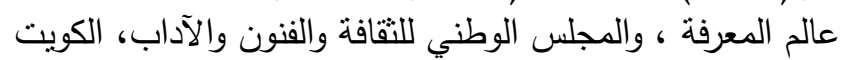

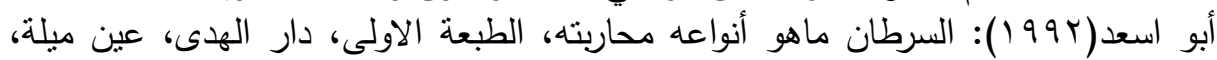
الجزائر

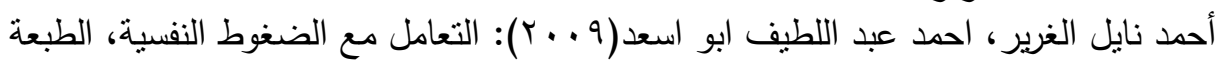

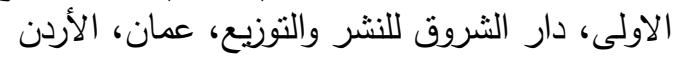

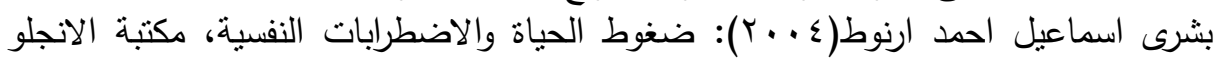

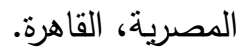

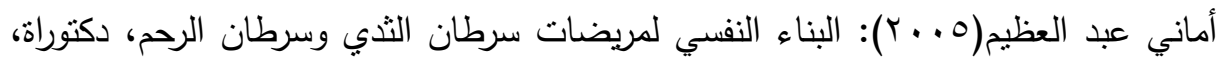

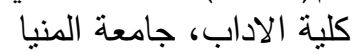

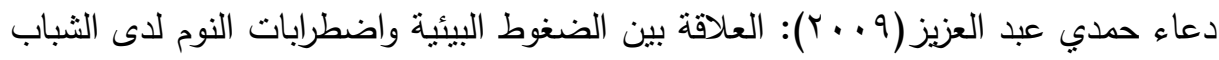

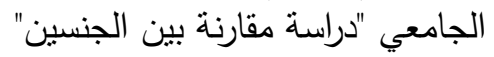

Edward P Sarafino ,(1994): Health psychology : biopsychosocial interactions, wily, New York.

Jean Benjamin stora (1993): le stress, Edition Dahlab, 2e, edition, paris ,france.

Scheitzer, N Daly et d'autre, Cancérologie clinique, 6eme édition, Masson, Paris.

Helgeson, \& Cohens, (1996) Cutrona, Russel, \&Rose, 1986; Revenson, Wollman \& Felton, 1983.

Hill,A;(2012): compassionate communication training with cacer patients and caregivers; Empathy seif- compassion and well- Being un publislad -M.A.University San Francisco. 
مجلة العلوم البيئية

معهذ الدراسات والبحوث البيئية - جامعة عين شمس البئ

\title{
AN ANALYTICAL STUDY ON THE \\ PSYCHOLOGICAL AND ENVIRONMENTAL \\ STRESSES ON UTERINE CANCERS PATIENTS \\ WITH AVERAGE ECONOMIC STANDARD
}

Karam El-Din, Leila, A. ${ }^{(1)}$; Eid, E. M. ${ }^{(1)}$ and Hassan, Heba, S, B. 1) Faculty of PostGraduate Childhood Studies, Ain Shams University

\begin{abstract}
The cancer and tumors that are formed are divided into two parts: benign tumors that are at a certain extent and do not spread away from their place of origin and are not serious if they are detected and treated quickly and removed from the body. And cancerous malignant tumors spread in parts of the body and can not be controlled and often ends with the death of infected. This study belongs to the pattern of analytical descriptive studies as the most appropriate types of studies suitable to the nature of the subject of the study, which aims to describe and analyze the psychological and environmental stress of patients with uterine cancer of the average economic level, and our desire to know behavioral problems scientifically help us in prevention and treatment to provide a facet of care (Medical, social and psychological), and then we can get facts through information and interpret them and then draw conclusions and develop indicators that help reduce the psychological and environmental stress of patients with uterine cancer. The current study on the tools was based on the psychological and environmental stress measures for patients with uterine cancer and the actual sample: After verifying the validity of the measurement instrument and its stability, the questionnaire was distributed to the sample of the study. The researcher distributed 100 forms and retrieved (84) (14) form is not valid for statistical analysis, and therefore the actual sample of (70). The overall score in the table indicates that the psychological stress of

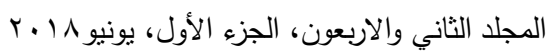


the sample of the study was high. The mean of the total score after the psychological pressure (2.35) and the standard deviation (0.348) and the percentage of $(78.33 \%)$, while the value of $t$ was 7.176 at a significant level of 0.05 , which indicates a decrease in the dispersion in the views of the sample of the study and convergence of views and note that the phrase ((29) God can heal me, I call it)) has obtained the highest averages, (2.79) and by a standard deviation (0.508), and a percentage of (91\%) (20) did not receive the appropriate psychological support from the husband () at the lowest averages (1.63), with a standard deviation of (0.705) and a percentage of $(54.33 \%)$. (Low). In the light of the research procedures and the results we have obtained and the quantitative and qualitative explanations we provide, we offer a number of recommendations and suggestions to expand the field of treatment of cancer diseases by integrating the psychological care of cancer patients in the field of health services and making them an important component of medical treatments. Emotional and psychological problems that may be exposed to patients as a result of cancer.

Keywords: Psychological stresses., Environmental stresses., Uterine cancer. 